\title{
Dos emisarios del general José de San Martín en el Perú: Remigio Silva y Fernando López Aldana ${ }^{1}$
}

\section{Two emissaries of General José de San Martin in Peru: Remigio Silva and Fernando López Aldana}

Víctor Peralta Ruiz ${ }^{2}$

CSIC, Madrid

\section{Resumen}

Este artículo rescata del olvido historiográfico a dos personajes: el limeño Remigio Silva y el bogotano Fernando López Aldana. En distintos contextos, ambos asumieron papeles clave como emisarios del general José de San Martín antes de su desembarco en el Perú. Silva tuvo un papel relevante en el éxito de la expedición naval de Lord Cochrane, mientras que López Aldana fue divulgador de la propaganda sanmartiniana en Lima. Los protagonismos de Silva y López Aldana fueron

1 Investigación realizada dentro del proyecto I+D HAR2016-77609-P, financiado por la Agencia Estatal de Investigación (Ministerio de Economía, Industria y Competitividad) y el Fondo Europeo de Desarrollo Regional. Apoyada igualmente por el Proyecto Intramural de Incorporación de Investigadores al CSIC con número de referencia 2018101107.

2 Científico titular del Consejo Superior de Investigaciones Científicas (CSIC) en Madrid. Director de Revista de Indias. Es autor de En defensa de la autoridad. Política y cultura bajo el gobierno del virrey Abascal. Perú 1806-1816 (Madrid, 2002); La independencia y la cultura política peruana 1808-1821 (Lima, 2010). Ha editado con Dionisio de Haro, España en Perú (1796-1824). Ensayos sobre los últimos gobiernos virreinales (Madrid, 2019) y con Ivana Frasquet, La revolución politica. Entre autonomias e independencia en Hispanoamérica (Madrid, 2020). Correo: victor.peralta@cchs.csic.es. ORCID: 0000-0002-4098-2104 
cardinales en la guerra de zapa dentro del Virreinato, que conectó simultáneamente a rioplatenses, chilenos y peruanos.

Palabras clave: emisarios sanmartinianos, Perú, independencia, Remigio Silva, Fernando López Aldana

\section{Summary}

This article rescues two characters from historiographical oblivion: Remigio Silva from Lima and Fernando López Aldana from Bogotá. In different contexts, both assumed key roles as emissaries of General José de San Martín before his landing in Peru. Silva played a relevant role in the success of Lord Cochrane's naval expedition, while López Aldana was a popularizer of San Martín propaganda in Lima. The prominence of Silva and López Aldana was key in the "undercover war" within the viceroyalty that simultaneously connected Rio de la Plata, Chileans and Peruvians.

Key Words: San Martin emissaries, Peru, Independence, Remigio Silva, Fernando López Aldana

\section{Introducción}

La historiografía de la independencia en el siglo XIX y prin-

180 cipios del XX estudió a los emisarios sanmartinianos en Lima desde una óptica nacionalista. Para estos historiadores, personajes como Remigio Silva o José de la Riva Agüero destacaron por actuar aisladamente para promover la emancipación antes de la llegada del general José de San Martín. ${ }^{3}$ Más contemporáneamente, bajo la perspectiva historiográfica que

3 Para un estado de la cuestión sobre la tesis aislacionista de los emisarios sanmartinianos en la historiografía, véase Peralta Ruiz (en prensa). 
sostuvo el discurso de la independencia concedida, abordar el tema del patriotismo antes de la llegada del Ejército Libertador resultaba superfluo, debido a que la población limeña había sido cómodamente complaciente con el régimen virreinal. En este artículo, se cuestionan ambas aproximaciones: la primera, por proyectar una versión descontextualizada del entorno en el que actuaron los emisarios sanmartinianos en el Perú; la segunda, por menospreciar la trayectoria de personalidades que arriesgaron sus vidas a sabiendas de que actuaban en un lugar neurálgico del poder realista.

Lo que este trabajo se propone comprobar, en primer lugar, es que la actuación de los agentes o corresponsales sanmartinianos debe comprenderse como una conexión simultánea rioplatense, chilena y peruana. Por ese motivo, en este artículo, se hará el estudio biográfico de dos personajes que intervinieron en la incipiente red de espionaje que precedió al arribo de la Expedición Libertadora de San Martín. Los emisarios seleccionados son Remigio Silva (Lima, 27 de octubre de 1782-20 de noviembre de 1854) y Fernando López Aldana (Santa Fe de Bogotá, 30 de mayo de 1784-Lima, 2 de junio de 1841). Se reconstruirán, primero, las actividades políticas de estos dos personajes previas a su conversión en emisarios y, luego, su corta actividad al servicio de la causa sanmartiniana.

En segundo lugar, se argumentará que el desempeño de estos dos personajes fue obstaculizado no solo por el Gobierno virreinal -en su intento por desarticular la guerra de zapa ideada por el general San Martín-, sino también por otros emisarios patriotas que recelaron de su protagonismo. Al comprobar el argumento anterior, se demostrará que el universo de los emisarios sanmartinianos fue bastante heterogéneo y hasta contradictorio, cuando no salpicado de enfrentamientos entre sus protagonistas. Así, si bien la actuación de los emisarios respondió a una intrincada y compleja red externa de 
carácter secreto originada en Chile y las Provincias Unidas del Río de la Plata, esta también estuvo integrada por grupos de patriotas limeńos que ocasionalmente debieron colaborar entre sí pese a su desconfianza mutua.

La detallada clasificación de los patriotas en Lima, según su vínculo institucional, en vísperas de la independencia que Germán Leguía y Martínez incluyó en su Historia de la emancipación del Perú: el protectorado (tomo VII) (1972), resulta útil para los objetivos de este artículo. El historiador mencionó la existencia de, al menos, tres redes patrióticas. La primera la habrían integrado los fernandinos y carolinos, es decir, los médicos de la Facultad de Medicina de San Fernando y los estudiantes del Convictorio Carolino. La segunda red habría estado conformada por los neris, deanes y forasteros, vale decir, los clérigos del Oratorio de San Felipe Neri, la logia patriótica de la huerta del deán chileno José Flores, y el club de los forasteros, integrado por el santafereño Fernando López Aldana y el chileno Joaquín Campino. Finalmente, identificó un tercer grupo, a los que denominó los copetudos, asociado con la logia secreta promovida por la alta nobleza limeńa liderada por José de la Riva Agüero (Leguía y Martínez, 1972, tomo II, pp. 237-283). Si bien la interpretación de Leguía y Martínez suscribió el discurso del patriotismo aislado, su clasificación resulta útil en la medida en que permite resaltar el lugar ocupado por los emisarios dentro de los heterogéneos grupos de patriotas limeños por él identificados. Así, la historiografía vinculó las actividades secretas de Remigio Silva con la actuación propagandística de los aristocráticos copetudos limeños. Incluso, Mariano Felipe Paz Soldán aventuró que Silva actuó, en ocasiones, como amanuense de escritos dirigidos a San Martín que, en realidad, fueron inspirados por José de la Riva Agüero. Por su parte, el propio López Aldana, en varios folletos reivindicativos que publicó en la primera mitad del siglo XIX, resaltó la existencia de una red patriótica de emigrados forasteros residentes en Lima que él lideró. El 
cometido de este trabajo es esclarecer, en tanto las fuentes lo permitan, la actuación de ambos personajes.

\section{Remigio Silva y el entramado rioplatense-chileno}

En octubre de 1809, Remigio Silva fue incluido en un procesamiento criminal en la Audiencia de Lima por tramar una conspiración armada con su hermano, el abogado José Mateo Silva, y otros personajes más, supuestamente, con el propósito de lograr la destitución del virrey Abascal. Todos ellos habrían estado de acuerdo en la necesidad de constituir una junta de gobierno en nombre de los derechos de Fernando VII, tal como se había conformado en la ciudad de Quito. Por entonces, Remigio Silva tenía 27 años y se desempeñaba como subteniente del regimiento de milicias El Fijo de la ciudad de Lima. Eran también conocidos sus "tratos de comercio" en el próspero negocio que regentaba su padre, Toribio Silva, en la calle de San Lázaro y otros céntricos barrios limeños. De poco valieron estos antecedentes para librar a Remigio de un procesamiento en el que el fiscal Pareja solicitó la aplicación de la pena de muerte para él y los demás acusados. ${ }^{5}$ El procurador, con la intención de corroborar la inocencia de Remigio, presentó una serie de testigos que coincidieron en afirmar que este, por su prudencia, austeridad y devoción religiosa, no podía haber participado en una conspiración de ese calibre. Tan convencido estaba el procurador de la inocencia de su defendido que, premoni-

4 AGI Lima, leg. 740, "Cuaderno cuarto de los autos hechos en Lima en 1809 , como motivo de la sublevación intentada en aquella capital por D. Mateo Silva y otros".

5 "Expediente del coronel don Remigio Silva que presenta al soberano Congreso, suplicando que por sus padecimientos y servicios rendidos en favor de nuestra independencia desde el año de 1809 hasta el de 1820, se le conceda el retiro con el sueldo íntegro de coronel que lo es por autoridad legítima desde el año de 1823” (en Silva, 1921, p. 3). 
toriamente, afirmó que "él saldrá desde luego de las manos de la justicia: mas le quedará para siempre gravada en lo más íntimo de su corazón la severidad del Señor Fiscal, que ha pedido su cabeza como reo de lesa majestad" (Eguiguren, 1957, tomo 1, p. 85).

Silva, finalmente, fue el único liberado del proceso y los cargos en su contra fueron retirados. Su hermano y el resto de acusados fueron condenados a prolongadas penas de presidio fuera del Virreinato. Uno de estos, el gallego Antonio Pardo, apenas conoció que su condena de reclusión en la metrópoli también le obligaba a correr con las costas del juicio, solicitó que esta "se extienda también contra los dos hermanos Silvas, que han sido juzgados en esta causa, por tener bienes conocidos" (Eguiguren, 1957, tomo 2, p. 227). Este pedido prosperó y Toribio Silva tuvo que deshacerse de parte de sus propiedades para afrontar el pago del juicio en el que se procesó a sus dos hijos (Silva, 1921, p. XXII). A pesar de su absolución, el Gobierno de Abascal mantuvo en delante una continua vigilancia sobre las actividades futuras de Remigio Silva y su familia.

El resentimiento de Remigio Silva hacia los magistrados del régimen virreinal por la arbitrariedad cometida en contra de él y de su familia se afianzó cuando, en 1816, se produjo el repentino fallecimiento de su hermano Mateo en el hospital de Bellavista, habiendo sido antes trasladado a las casas-matas del Callao tras su evacuación de la prisión de Bocachica en Cartagena de Indias (Vicuña Mackenna, 1860 , p. 121). También por esa fecha se produjo el deceso de su padre, circunstancia que Remigio vinculó con el declive económico del negocio familiar y la desolación que a aquel le provocó la muerte de su hermano. La ocasión propicia para cobrarse la afrenta recibida por el régimen virreinal, al que ya no dudaba en considerar como de naturaleza tiránica, se presentó para Remigio de una manera fortuita 
en octubre de 1817. En esa fecha, tras la victoria de Chacabuco por parte del ejército de los Andes, que supuso la caída del régimen de Marcó del Pont y la proclamación de la independencia de Chile, el general San Martín propuso al virrey Joaquín de la Pezuela un canje de prisioneros con el propósito de "humanizar" el conflicto bélico en la América meridional. Fue esa la circunstancia que Silva aprovecharía para, voluntariamente, pasar a integrar la primera red de confidentes sanmartinianos en Lima.

El propósito oficial de la negociación entablada entre San Martín y Pezuela fue canjear a los realistas que se mantenía prisioneros en Chile y las Provincias Unidas del Río de la Plata por los oficiales y soldados patriotas confinados en Lima tras la derrota experimentada por el último ejército auxiliar del Perú rioplatense en la batalla de Vilcapugio. La misiva que San Martín dirigió al virrey con fecha 30 de octubre de 1817 fue confiada al sargento mayor rioplatense Domingo Torres en su condición de comisionado parlamentario. ${ }^{6} \mathrm{Al}$ arribar al Callao, este fue recibido por el virrey, pero se le impuso una vigilancia extrema en el lugar donde fue alojado. No obstante, se sabe que varios "patriotas peruanos se dieron maña para burlar estas precauciones y ponerse en comunicación directa" (Mitre 1889, tomo II, p. 509) con Torres. Entre estos, estuvo Brígida Silva, hermana de Remigio, quien comunicaría a este la misión fundamental que, secretamente, había venido a cumplir el comisionado rioplatense.

En realidad, Torres era la punta de lanza de la guerra de zapa

6 Torres, nacido en Montevideo en la época del autonomismo bonaerense se enroló en el ejército rioplatense que combatió a los realistas en la Banda Oriental. En 1817, se trasladó a Chile como ayudante del general Juan Ramón Balcarce. Fue nombrado emisario de San Martín en el Perú en sustitución de Tomás Guido, quien había sido elegido por el Gobierno de Buenos Aires para cumplir esa misión. 
ideada por San Martín para debilitar a los gobiernos realistas. Fue contra el gobernador de Chile, Marcó del Pont, contra quien por primera vez se aplicó esta estrategia. Esta consistió en enviar emisarios con el propósito de asestar un inicial daño "moral" al régimen realista a través del fomento de las deserciones en sus milicias, batallones y tropas, la difusión de propaganda patriótica clandestina, y la recolección de información logística proclive a ser usada por el ejército patriota (Pavón Pereyra, 1971). Esta estrategia se amplió al Perú tras el triunfo de Chacabuco. Para lograrlo, San Martín confió secretamente a Torres unas "Instrucciones reservadísimas que observará cautelosamente”. En ese documento, se fijó como uno de los objetivos principales de su comisión examinar el estado político y militar de Lima "y el de los demás gobiernos del continente meridional", concretamente, de Quito, Santa Fe y Caracas. También se le solicitó "tomar idea de los sujetos más distinguidos por su patriotismo, la influencia ante el pueblo, la opinión dominante de este, la que le merezcan las armas de las Provincias Unidas, su disposición al Señor Virrey y el grado a que haya subido la diferencia de opiniones entre los constitucionales y siervos de Fernando" (CDIP, tomo VIII, vol. 1, p. 332). En suma, se trataba de aplicar una guerra psicológica a través de emisarios - previa o posteriormente comprometidos- con la tarea de sembrar la desmoralización y desconcierto en el alto mando realista peruano. Para lograr su cometido, el Gobierno chileno entregó a Torres una cantidad de onzas de oro por un valor de diez mil pesos que este debía distribuir, preferentemente, entre los militares rioplatenses confinados en la prisión limeña.

Uno de los primeros beneficiarios de la ayuda económica de Torres fue José Bernáldez Polledo, nacido en Galicia y convertido en un simpatizante del autonomismo rioplatense tras el estallido de la Revolución de Mayo de 1810. Este se integró en su condición de teniente coronel en el ejército auxiliar del Perú que combatió en la Audiencia de Charcas contra el ejér- 
cito realista (Olivero, 2009, tomo VIII, pp. 157-158). Al ser tomado prisionero en la batalla de Vilcapugio, fue conducido a la prisión del Callao. Unas semanas antes de la llegada del comisionado parlamentario, Bernáldez Polledo logró fugarse de este presidio posiblemente ayudado por Brígida Silva. La Junta de Purificación de 1821 comprobó que la hermana de Remigio comenzó esta actividad clandestina con sus propios familiares presos en la abortada conspiración de 1809, y las continuó con visitas realizadas a Ramón Anchoris, un reo de origen rioplatense acusado de liderar una nueva conspiración contra Abascal en setiembre de 1810. Concretamente, Brígida afirmó sobre esto último que, "en la prisión del cura Tagle y su hermano, introdujo las instrucciones al licenciado don Ramón Anchoris, que se hallaba en Santa Catalina con centinela de vista" (Silva, 1921, p. 153). ${ }^{7}$ Remigio Silva completó la acción de su hermana al ocultar y proteger a Bernáldez Polledo en su vivienda de Huacho durante un ańo; de este modo, burló la vigilancia de los agentes políticos del virrey (Mitre, 1889, tomo II, pp. 511-512). Relata Silva que, un día, cuando ambos pugnaban por localizar una embarcación que les trasladase clandestinamente a Buenos Aires, tuvieron noticia del arribo de Domingo Torres al Callao. Sus planes cambiaron y

a fuerza de los más grandes trabajos, por la estrictez en que tenían a este señor en la Artillería, pudimos comunicarnos con él, en todos los días, resultando así él noticiado de lo más mínimo de aquel gobierno y por fin le mandamos a bordo, cuando estuvo embarcado, en lo interior de 4 cajetas de dulce, una instrucción muy circunstanciada en tres o cuatro pliegos, escrita toda de esta letra mía, en que le comunicamos la fuerza que con Osorio había caminado para este Chile. (Silva, 1921, p. 63)

7 “Año 1821-Junta de Purificación. Doña Brígida Silva”.

8 "Expediente del coronel del Perú, don Remigio Silva sobre importantes servicios que ha hecho a esta nación chilena, cuyos gastos reclama al so- 
Silva se refería al conocido y extenso informe del 18 de diciembre de 1817, atribuido por la historiografía a Bernáldez Polledo, en el que este daba cuenta pormenorizada a su paisano de "la fuerza física y moral del ejército [realista] que llaman expedicionario" y que partió a reconquistar Chile (Comisión Nacional del Centenario, 1910, tomo VII, pp. 16-33). Este documento, además de explayarse en la composición de los batallones, regimientos y artillería del ejército realista del brigadier Mariano Osorio, se ocupó de la fuerza efectiva que quedó acantonada en la capital, así como del estado moral de la población peruana tanto en Lima como en las provincias interiores (Alvarado Luna, 2015).

De manera exagerada, el informe de Bernáldez Polledo destacó que las poblaciones de la mayoría de las provincias peruanas eran "adictas a nuestro sistema" de gobierno libre. Respecto del estado moral en Lima, el referido informe dividió a la población en cuatro clases: los criollos limeños o naturales del país; los provincianos avecindados o de paso; los europeos; y, por último, los pardos y morenos. Se destacó las peculiaridades constitutivas de estas clases, como la debilidad de espíritu de los criollos a causa del clima; la fibra y reflexión de los provincianos; la vacilación y conservadurismo de los europeos; y la animadversión hacia criollos y europeos de los pardos y morenos. El informe concluía que estas clases en Lima por la libertad de su patria

no harán por sí nada; son incapaces de todo movimiento propio y aptos únicamente para recibir impulso exterior. En una palabra, en este país, en donde brilla en sumo grado la literatura, los hombres no tienen otra disposición que para obedecer a cualesquiera que los mande. (Comisión Nacional del Centenario, tomo VII, p. 28)

berano congreso en este año de 1849". 
Si bien Remigio Silva confesó que su papel en la redacción del referido informe fue actuar como amanuense de Bernáldez Polledo, no resulta aventurado pensar que su previo conocimiento acerca del estado de ánimo de las provincias peruanas influyera en la redacción final de dicho texto. Esta suposición se afianza cuando se compara la similitud de las afirmaciones sobre el estado moral del Perú vertidas en el informe de Bernáldez Polledo con las presentadas en los textos atribuidos a Silva por Mariano Felipe Paz Soldán, como se verá más adelante.

A través de su apoyo logístico en las cárceles y del sostenimiento económico de Bernáldez Polledo, "un hombre cargado de años, pero de [buen] corazón y cabeza”, en palabras de Mitre, los Silva quedaron vinculados a la red política secreta que alentó el plenipotenciario Torres. Así, gracias también a Brígida Silva, "pudo Torres entablar correspondencia con López Aldana, Riva Agüero y Quirós” (Mitre, 1889, tomo II, p. 510). En aquella coyuntura, Silva se convirtió en "secretario u órgano del grupo de los 'carolinos' y aún de los 'copetudos"” (Leguía y Martínez, 1972, tomo II, p. 378). Todos estos grupos limeños quedaron, de este modo, vinculados a la primera red rioplatense-chilena. Por su parte, Remigio Silva realizó con Bernáldez Polledo una serie de actividades clandestinas en Lima, Huarmey y Huacho a lo largo de 1818, relacionadas con la obtención de información y tareas de propaganda. Silva conocía que, para lograr su cometido, Torres tenía asignada una cantidad de dinero e, incluso, sabía que había entregado treinta onzas de oro a Bernáldez Polledo, pero, lejos de reclamar cantidad alguna, confesó que "gasté yo, en dichos meses, más de dos mil quinientos pesos", en referencia a su peculio (Silva, 1921, p. 65).

Es posible que Silva y Torres llegaran a conocerse. Ello se desprende del "Expediente sobre servicios hechos a la nación chilena" que, en 1849, aquel elevó a las cámaras legislativas 
peruanas para obtener un reconocimiento económico. Silva se presentó como agente principal de la República de Chile en el Perú, "mi patria natal". En uno de los pasajes de su expediente, explicitó que Domingo Torres le nombró comisionado y plenipotenciario del Gobierno de Chile y "representaba yo en aquella época, de un modo oculto, a esa nación, para comunicarle todo acto que amagase su Independencia, por las medidas que tramaba el Virrey de esta capital" (Silva, 1921, p. 60). ${ }^{\text {? }}$

En enero de 1818, Torres retornó a Valparaíso en la fragata Amphion al cumplir con su cometido de ayudar económicamente a sus compatriotas confinados en Lima y, de paso, de recabar informaciones secretas por parte de estos y de los incipientes círculos patrióticos limeños. No menos efectivo fue el rumor que, a través de varios emisarios pagados, propagó en las provincias del Virreinato de que una expedición naval y militar llegaría pronto a sus costas para liberar al Perú. Lo primero iba a ocurrir un año después, cuando hizo su aparición en las costas peruanas la expedición naval chilena del almirante Lord Cochrane.

La conformación de la escuadra de Cochrane fue el resultado de la victoria militar de las tropas patriotas de José de San Martín y Bernardo O'Higgins sobre las fuerzas realistas de Osorio en Maipú el 5 abril de 1818. Este hecho consumó la independencia de Chile. O’Higgins, en su condición de director supremo, impuso la creación de una escuadra naval nacional para arrebatar al virreinato peruano la hegemonía sobre el mar. Cochrane, de origen escocés, fue el marino elegido para comandar una expedición encaminada a bloquear el puerto del Callao y, con ello, forzar una rebelión popular

9 "Expediente del coronel del Perú, don Remigio Silva sobre importantes servicios que ha hecho a esta nación chilena, cuyos gastos reclama al soberano congreso en este año de 1849". 
que se pensaba provocaría la rendición del virrey Pezuela. Los navíos chilenos del almirante británico arribaron a las inmediaciones del principal puerto limeño en los primeros meses de 1819 y, de inmediato, comenzaron sus maniobras encaminadas a acelerar el "descalabro moral" de los realistas.

Silva y Bernáldez Polledo fueron informados por buques procedentes de Chile, mediante señas convenidas de antemano, del arribo a la caleta de Ancón a principios de febrero de un navío chileno que formaba parte de la escuadra de Cochrane. En este, viajaban los emisarios limeños Francisco Fernández Paredes y José García, respectivamente Cario y Mario, a quienes el general San Martín había encomendado una importante misión secreta. ${ }^{10}$ Según el plan que ambos presentaron a San Martín en Santiago de Chile el 6 de noviembre de 1818, su compromiso fue constituir un batallón entre los criollos adictos a la liberación de Lima. Ambos limeños aseguraron que, una vez "realizada la formación de este cuerpo y puesto en marcha con la expedición [naval de Cochrane], deberá ocupar la vanguardia del ejército; descubrir la entrada menos expuesta a la ciudad en caso de resistencia, adelanta mucho nuestro triunfo; y facilitar embarazos de pronta ejecución, evita mayores descalabros en la masa del ejército" (Comisión Nacional del Centenario, 1910, tomo VII, pp. 92-93). Cario y Mario fueron financiados económicamente para lograr este cometido, pero ni lo cumplieron ni dieron mayores detalles acerca de su fracaso al oficial rioplatense y secretario de San Martín que era su enlace directo, Antonio

10 Francisco Fernández Paredes, nacido en Lima en el seno de una acomodada familia de la aristocracia, participó como oficial en el ejército realista derrotado en la batalla de Maipú. Tras su captura, conoció a San Martín y se convirtió a la causa patriótica. De José García, también nacido en Lima, apenas se sabe que combatió en el ejército realista en el Alto Perú y que, en algún momento, desertó y se trasladó a Chile para enrolarse en las filas patriotas. 
Álvarez Jonte, quien se desempeñaba como auditor de guerra en la nave almiranta de Cochrane.

Afirmó Leguía y Martínez que Silva esperó a Cario y a Mario en Ancón y "después de enterrar en las arenas la correspondencia más peligrosa, guio y condujo a sus recomendados hasta Lima" (Leguía y Martínez, 1972, tomo II, p. 383). Pero según confesó el propio Silva en su Expediente de 1836, él conoció a Cario y Mario en Lima en casa de un tío suyo. Allí se enteró de que estos no habían podido enviar ningún tipo de información a la escuadra chilena de Cochrane, por lo que "me resolví a ir a dicha escuadra por la costa" para cumplir con dicho objetivo. Sorpresivamente, esta iniciativa fue censurada por los dos emisarios mediante "un oficio, sumamente agrio que me mandaron" -afirma Silva-y en el que incluso, para hacerle fracasar en su empeño, le demandaron la devolución de los doscientos pesos que, previamente, le entregaron para tareas de propaganda. Cario y Mario advirtieron a Silva que harían lo posible por frustrar la misión en la que se había empeńado, pero este hizo caso omiso de sus advertencias (Silva, 1921, p. 65). Esta circunstancia demuestra el exceso de celo y competitividad que existió entre los emisarios sanmartinianos peruanos, al punto de no dudar en boicotearse unos a otros pese a compartir el común objetivo de servir a la causa patriota.

Roto todo contacto con Cario y Mario, el plan de Silva consistió en dirigirse a Huacho, donde abordó un bergantín que 192 lo condujo al Callao. Allí, se entregó como prisionero a una de las naves bloqueadoras de Cochrane, la Chacabuco, el 30 de marzo de 1819. Se produjo de este modo la segunda conexión voluntaria de Silva con una red secreta sanmartiniana en la que el protagonismo principal debía haber sido asumido por Fernández Paredes y García. Tras aclarar a sus captores que cumplía la misión de informante en su condición previa de corresponsal de Chile con Domingo Torres, Remigio Silva 
fue conducido a la almiranta O'Higgins y presentado a Álvarez Jonte y Cochrane. Silva logró superar las iniciales suspicacias del edecán y el almirante al ofrecerles su apoyo logístico para conseguir agua y víveres, cuya alarmante escasez advirtió entre la tripulación. Silva convenció a Álvarez Jonte de que su idea de abastecerse a la desesperada en Chancay -incluso bombardeando dicho poblado- "era en el todo infructífero, porque después de que era imposible hacer allí aguada, era también incapaz de hacerse víveres, a causa de que los ganados están algo retirados del puerto" (Silva, 1921, p. 69). El conocimiento de Silva del llamado Norte Chico lo condujo a recomendar que los reabastecimientos de la escuadra debían hacerse en las caletas de Huacho y Supe, donde el riesgo era mínimo por no haber guarniciones realistas de importancia en sus alrededores. Silva afirma que, al mismo tiempo que Álvarez Jonte supo del destino de Cario y Mario por medio del agente Juan Franco, "dimos la vela para seguir el plan ya dicho. Llega la Escuadra a Huacho; hace su aguada con toda tranquilidad, sin el más pequeño riesgo, como lo había yo dicho. Llega a Supe, hace sus víveres a toda satisfacción y de cuanto apetecieron" (Silva, 1921, p. 72).

Durante el tiempo que se prolongó el bloqueo naval y ante la ausencia de nuevas noticias sobre Cario y Mario, Álvarez Jonte no solo confirmó a Remigio Silva como corresponsal del Gobierno chileno en el Perú, sino también como su principal confidente acerca de la situación interna del Virreinato. Para lograrlo, aquel instó a este a difundir entre los patriotas de Lima una instrucción de ocho puntos que requería con urgencia San Martín. Estas instaban a proporcionarle cualquier información fidedigna sobre los recursos económicos del Gobierno virreinal y el estado de sus tropas, el plan de operaciones realista en caso de ser atacada Lima, el grado de fidelidad de la capital y las provincias respecto del régimen de Pezuela, las identidades de los espías del Gobierno en Chile y Buenos Aires, etcétera (López Aldana, 1869, p. 28). 
Silva fue desembarcado en una caleta aledaña a Lima y, por un tiempo, reemprendió sus tareas de contacto con diversos grupos como los copetudos de Riva Agüero, los forasteros de Fernando López Aldana y otros más. Años después, Silva afirmaría que fue "sobre infinitos riesgos" como continuó su misión de ayudar a la causa del general San Martín "dando aviso de fuerzas, etc., etc., y cuanto he creído preciso sea noticiado" (Silva, 1921, p. 73). En esta etapa, su aporte más importante fue un extenso manuscrito firmado en Lima el 20 de diciembre de 1819 bajo el seudónimo de El Ciudadano de Lima y que Paz Soldán no dudó en atribuirle. Este documento debe ser considerado como su respuesta a la instrucción de Álvarez Jonte que recibió en la O'Higgins.

Titulado como "Manifiesto que hace un ciudadano de Lima, a los Estados de Buenos Ayres y Chile", el manuscrito redactado por Silva en diciembre de 1819 se inicia con un optimista resumen de su contenido: "lo sustancial de este papel, es el voto absoluto y uniforme de todos los patriotas de esta capital que componen la mayor y mejor parte de su población, los que [a no ser tan sumamente riesgoso] seguramente plantarían todos sus firmas y caminaría este, autorizado con miles de ellas" (Paz Soldán, 1868, p. 357). Su exposición se dividió en seis puntos, considerados como una respuesta al referido documento interrogatorio del secretario de San Martín:

1. El tiempo de los papeles y proclamas moralmente desestabilizadores ha concluido y es la hora de las tropas, cañones y balas.

2. Las tropas deben estar integradas por al menos cuatro mil hombres y el bloqueo del Callao se debe mantener.

3. El gasto del envío de tropas se compensará por la abundancia de víveres y plata que estas hallen en el lugar donde desembarcasen. 
4. La expedición enviada por Chile y Buenos Aires debe ser numerosa, aunque se corra el riesgo de revoluciones en su interior.

5. Sin vencer al Perú, jamás habrá tranquilidad para Buenos Aires y Chile, ni serán reconocidas sus independencias.

6. Cualquier opinión en contra de la remisión de tropas debe ser considerada como traición a la patria.

Bajo este último concepto se refirió no solo al Perú, sino a Chile y a las Provincias Unidas del Río de la Plata, ya que Silva consideró que "cuando digo a mi patria, hablo como juzgo debe hablar, tomando como americano que soy, a todos esos Estados como míos" (Paz Soldán, 1868, p. 358). En una nota ańadida al final de su escrito, Silva añadió que su papel pudo ser conducido a Chile recién el 3 de enero de 1820 por medio del "caballero Portales".

La última comunicación de Silva a San Martín se redactó en Lima el 11 de marzo de 1820 (Comisión Nacional del Centenario, vol. 7, pp. 169-173). En esta carta, cuyo contenido era más personal que informativo, le trasladaba su duda inicial respecto de la posibilidad de embarcarse en la fragata inglesa Hércules con dirección al sur para integrarse en la Expedición Libertadora o, por el contrario, dirigirse a Supe o Barranca para continuar su tarea logística de preparar informes confidenciales para su remisión a Chile. Silva confesó a San Martín que, finalmente, era mejor refugiarse en Supe "que es de gente tan adicta y al que sus vecinos y los más deudos míos, todos los días me llaman” (Comisión Nacional del Centenario, vol. 7, p. 171). Desde allí, ofreció continuar recabando datos sobre la fragata realista Prueba para su deseable captura, información que se propuso escribir en hojas "hasta por quintuplicados; para mandarlos por todas vías, a fin de lograr el que sean entregados, si se encuentra algún buque de la escuadra [de Cochrane] por las partes por donde viajan" (Comisión Nacional del Centenario, vol. 7, p. 172). 
Concluía Silva su mensaje expresando su satisfacción por haber conformado una red de jóvenes informantes que actuaba entre Supe y el Callao "llenando así mis deberes" (Comisión Nacional del Centenario, vol. 7, p. 172).

La afirmación de Leguía y Martínez de que Silva habría usado el seudónimo de Aristipo Emero ${ }^{11}$ para redactar los comunicados de la logia de Riva Agüero obliga a pensarle al menos como coautor de otros dos escritos: la "Relación de Lima", fechada el 16 de marzo de 1819, y el "Informe sobre el estado del virreinato", redactado sin fecha precisa, pero claramente con posterioridad al primero (Comisión Nacional del Centenario, vol. 7, pp. 116-119 y 185-196). El contenido de la "Relación", a diferencia de otros escritos similares, no proporciona ningún juicio de valor. Se puede decir que los datos proporcionados pretendieron ser objetivos y, entre otros, apuntaron a esclarecer el estado de la política de empréstitos del Virreinato para cubrir su urgente necesidad de gastos militares; la estrategia defensiva diseñada por los realistas ante posibles lugares de desembarco de una expedición procedente de Chile; la identificación de los principales asesores de Pezuela; etcétera.

Para propósitos de un análisis discursivo, mucho más interesante resulta la posterior "Información de Aristipo Emero". En este documento, se vuelve a abundar en los planes confeccionados por el régimen virreinal para contener la ofensiva patriota desde el sur. En un pasaje de este documento, se confirmaría la autoría de Silva, tras plantear este una ofensiva patriota solo concebible en un personaje que conoce el norte limeño: "yo soy de opinión aunque no lo entiendo, por no

$11 \mathrm{Al}$ respecto, Leguía y Martínez expresó de Silva que "son muchos los instrumentos existentes para su infatigable y abnegada faena libertaria, ya autorizados con el seudónimo de Aristipo, ya firmados con el lema de un ciudadano de Lima" (Leguía y Martínez, 1971, tomo II, p. 381.) 
ser militar, que si pudieran desembarcar con mucho sigilo tres o cuatro mil hombres de buena tropa en Supe donde inmediatamente se asegura que se reunirán hasta doscientos hombres de los pequeños pueblos de Pativilca, Barranca y Supe, por ser tan adictos que sólo por falta de armas no se han sublevado [...] inmediatamente ocurriría el virrey a ese punto con toda su tropa; tendría que sacar del Callao la mayor parte" (Comisión Nacional del Centenario, vol. 7, p. 188). Tras comprobarse que la capital había quedado desguarnecida -continúa Aristipo Emero- sería ese el instante propicio para desembarcar en Pisco un ejército de seis mil u ocho mil hombres "con lo cual quedaría desconcertado este gobierno". Esta maniobra atenazadora, finalmente concluye la información, debería ser completada por un incesante cañoneo de la fortaleza del Callao por parte de la escuadra naval bloqueadora. La caída del Gobierno virreinal quedaría asegurada.

Una de las afirmaciones de la "Información de Aristipo Emero" más citada por historiadores, como Jorge Basadre, ha sido la que hace referencia al compromiso de los limeños con su liberación política:

la opinión de los patriotas Lima es favorable a la independencia, pero es de advertir que hay patriotas de la clase alta, media y baja. Los de la clase alta, aunque deseen la independencia, no darán sin embargo ni un paso ni un peso para lograrla o secundarla [...]. Los de la clase media que son muchos, no harán tampoco nada activamente hasta que no vengan los libertadores y les pongan las armas en la mano [...]. Los de la clase baja que comprende este pueblo, para nada sirve, ni son capaces de ninguna revolución. (Comisión Nacional del Centenario, vol. 7, p. 190)

En cierto modo, con esta afirmación, Aristipo Emero proporcionó un respaldo contundente a la argumentación histórica que sostenía la existencia en Lima de un sentimiento resignado de que la independencia debía ser conseguida por un 
ejército libertador extranjero. Nuestro incognito personaje añadió que del patriotismo limeño no cabía esperar "ningún movimiento que favorezca los del ejército protector, de esta capital; pues en ella reina una indolencia, una miseria, una flojedad, una insubstancialidad, una falta absoluta de heroísmo, de virtudes republicanas tan general, que nadie resollará aunque vean subir al cadalso un centenar o dos de patriotas" (Comisión Nacional del Centenario, vol. 7, p. 190). Es más, al realizar Aristipo Emero un breve recuento de las seis conspiraciones ocurridas en la capital desde 1809, destaca que, en ninguna de ellas, "ha entrado ninguna persona de talento, calidad, ni caudal. Todos han sido hombres ordinarios, infelices o sin talento" (Comisión Nacional del Centenario, vol. 7, p. 191). Resulta extraño que, si el autor de la información fuera Remigio Silva, enfilase con este tipo de descalificativos contra la conspiración en la que participaron él y su hermano Mateo. Esta contradicción entre el discurso y la práctica obliga a matizar la concesión de la autoría total del texto a Silva. En todo caso, se puede argumentar que el informe fue un escrito en el que este intervino junto con otros personajes del grupo de los forasteros, sin descartar a algún miembro de los fernandinos o carolinos.

La situación de Remigio Silva se tornó insostenible en el Perú tras la delación de sus actividades políticas que, ante el fiscal de la Audiencia, Toribio de Acebal, hizo el arrepentido emisario sanmartiniano José García luego de su captura. Mario, traicionando su inicial fidelidad a San Martín para halagar a Pezuela, identificó a Silva como uno de los integrantes de la red limeña que divulgaba escritos independentistas. Concretamente, García inculpó a Silva de repartir en Lima los impresos que llegaron con la expedición de Cochrane y, además, de participar en las tertulias celebradas en la casa de Domingo Aranda. Al preguntar el fiscal Toribio de Acebal a García qué más podía decir de Silva, este respondió: 
Que Remigio Silva es uno de los mayores enemigos que tiene el Rey porque es influyente y seductor. Él es el que llevó verbalmente las primeras noticias a Cochrane y el primero que fue a su bordo. Silva y Puig hicieron en Supe el cavildo abierto para sublevar el pueblo y las provincias interiores de la sierra y pidieron armas y gente, y porque no les dieron todos los auxilios que pidieron no interceptaron la comunicación a Lima que era lo que se proponían. Sigue en la actualidad correspondencia con los enemigos. Se oculta en Supe en casa de su primo Mateo Aranda el hijo, y en Lima en la habitación del padre Huapaya en los Estudios; todo lo cual lo sabe el que declara porque el mismo Remigio Silva se lo ha dicho, y es público y notorio entre todos los insurgentes. ${ }^{12}$

Debido a esta delación, el 26 de marzo de 1820, fueron apresados José de la Riva Agüero, Joaquín Mansilla, Cecilio Tagle, José Pezet, Félix Devoti, Eduardo Carrasco y Julián Morales. La orden de captura se hizo extensiva a Silva, quien, prevenido por sus amistades -entre ellos, Fernando López Aldana- el 26 de mayo de 1820 pudo abordar una de las últimas embarcaciones de la escuadra chilena que retornó al país del sur tras concluir el bloqueo del Callao. ${ }^{13}$

Apenas fijó su residencia en Valparaíso, Silva elevó a las autoridades políticas locales, el 20 de julio de 1820, un resumen de sus méritos y servicios como corresponsal por Chile de la independencia del Perú. Este documento estuvo respaldado por los testimonios de Cochrane y Álvarez Jonte, entre

12 Biblioteca Menéndez Pelayo, Santander. "Archivo Pezuela”. Cuaderno 8. , "Declaración de don José García”, f. 144.

13 En la anónima "Biografía de D. Fernando López Aldana”, publicada en El Comercio con ocasión de su fallecimiento, se afirma que López Aldana proporcionó a Silva, en la época de su persecución final en Lima, no solo quinientos pesos, sino también lo ayudó a beneficiar un pasavante que tenía aquel de Lord Cochrane para que pudiese fugar a Chile e, incluso, "le acompañó hasta el muelle, disfrazado ambos, Silva de marinero y López Aldana de oficial” (anónimo, citado en López Aldana, 1869, p. 18). 
otros. El comodoro inglés R. Forster, comandante del navío San Martín, calificó a Silva no solo como "benemérito" de la causa patriótica chilena, sino que lo recomendó como "acreedor de una remuneración de la supremacía, en premio de sus distinguidos méritos" (Silva, 1921, p. 77). El 12 de agosto, el general San Martín aseveró que "el benemérito patriota don Remigio Silva, superando los riesgos de la vigilancia del virrey del Perú, me ha dirigido, con bastante frecuencia sus comunicaciones muy importantes a mi conocimiento" (Silva, 1921, p. 83). Finalmente, el supremo director O'Higgins agradeció a Silva "los importantes servicios que ha prestado a la sagrada causa americana”. Como resultado de estos méritos comprobados, San Martín otorgó a Silva el grado de sargento mayor y lo integró en la Expedición Libertadora que estaba en vísperas de partir al Perú. Pero el otro propósito de Silva, lograr que el Gobierno chileno lo compensara económicamente por los gastos personales realizados para cumplir con su misión de corresponsal, fue aplazado indefinidamente.

Cuando el Ejército Libertador hizo su ingreso en Huaura en noviembre de 1820, Silva fue nombrado gobernador interino de esta ciudad. Después de proclamarse la independencia en Lima, San Martín premió a Silva el 12 de diciembre de 1821 con el cargo de contador de la Dirección General de Tabacos y con un sueldo de dos mil soles anuales. Cuando Riva Agüero fue elegido presidente de la república por el Congreso Constituyente, Silva fue promovido el 3 de marzo de 1823 a presidente del departamento de Huaylas y se benefició de un ascenso a coronel del Ejército. Pero esta protección política de la que disfrutó el exemisario limeño en la iniciación de la república, abruptamente, se interrumpió con la dictadura bolivariana. Su lealtad a Riva Agüero provocó que el libertador caraqueño lo considerase como un obstáculo político. Silva afirma que Bolívar le solicitó "se adhiriese a su persona, y le devolvería la Presidencia haciéndole de paso general" (Silva, 1921, p. 21), pero él se negó a aceptarla. Despojado 
de su cargo, Silva, en un principio, se refugió en Huamachuco, pero, al sentirse acorralado, junto con sus compañeros Novoa y Mancebo se entregó en Trujillo al general Antonio Gutiérrez de la Fuente. Por orden de Bolívar, Silva fue desterrado primero a Guayaquil; luego, a Panamá; y, finalmente, a Jamaica, donde fue confinado en un presidio. En 1828, Silva regresó al Perú. Al año siguiente, por instancia del general Agustín Gamarra fue nombrado prefecto del departamento de La Libertad. En las décadas de 1830 y 1840, Silva, infructuosamente, realizó varias gestiones ante los Congresos de Chile y del Perú para obtener en uno u otro país un retiro decoroso por sus servicios prestados como emisario sanmartiniano, reclamo que no se le concedió.

\section{Fernando López Aldana o el emisario forastero incómodo}

Fernando López Aldana fue hijo del médico y naturalista Sebastián López Ruiz, célebre por su descubrimiento de la quinina en las serranías aledañas a Santa Fe de Bogotá. En 1792, la familia se trasladó a Madrid, donde hasta los 13 años Fernando cursó sus estudios elementales. Entonces, su familia decidió residir en la capital del virreinato de Nueva Granada, lugar donde se graduó como bachiller en Leyes en la Universidad de Bogotá. En 1805, residió en Quito, debido a que su padre fue nombrado recaudador de la Real Hacienda. Por no alcanzar la edad de 26 años, "que el tribunal de Quito exigía para recibirse de abogado”, su padre lo envió a Lima para ejercer su profesión. En 1810, los certificados y títulos presentados al flamante Colegio de Abogados limeño le valieron para ser admitido como uno de sus miembros (Martínez Riaza, 1985, p. 31).

El decreto de libertad de imprenta de 1810 fue aprovechado por López Aldana para divulgar en Lima la noticia de la conformación de la segunda Junta de Gobierno de Quito, integrada por algunas personalidades que llegó a conocer 
durante su breve residencia en dicha ciudad. En esa tarea de propaganda, fue socorrido por Manuel del Río, hijo del impresor Guillermo del Río, con quien mantuvo una estrecha amistad. López Aldana fue el autor del Diario Secreto de Lima, un escrito que criticó el despotismo del virrey Abascal y que, en la época de la libertad de imprenta sancionada por las Cortes de Cádiz, circuló clandestinamente en Lima. Por entonces, López Aldana entabló correspondencia con el líder autonomista rioplatense Juan José Castelli, quien se encontraba combatiendo en el Alto Perú. En efecto, en la carta del 10 de marzo de 1811, López Aldana comentó a este su indignación por la indolencia mostrada por las autoridades del Perú ante la formación de juntas de gobierno que actuaban como depositarias de la soberanía de Fernando VII. Consideraba que Lima se había convertido, contrariamente, por instancia del "godoyista" virrey Abascal en la capital del despotismo espańol. El Diario Secreto no solo se impuso denunciar esa aberración histórica, sino, a su vez, instar a la población peruana a que recuperara el pleno ejercicio de sus derechos políticos. En su misiva, López Aldana adjuntó a Castelli varios ejemplares de su manuscrito y le solicitó su intermediación para que fuesen distribuidos en Buenos Aires. La junta de gobierno bonaerense, al tener conocimiento de la existencia del Diario Secreto, no dudó en solicitar a su autor su propósito de publicarla para atacar al virrey del Perú. El 13 de setiembre de 1811, López Aldana cumplió con remitir a Buenos Aires treinta y siete números del Diario Secreto de Lima con el pedido de que "es útil que se imprima en vuestra ciudad, y para que después recibamos aquí numerosos ejemplares, destinados a sembrar la desesperación hasta en el seno mismo de nuestros tiranos" (Burzio, 1964, p. 311). Pero lo que se publicó en la Gaceta de Buenos Aires entre el 21 de mayo y el 15 de agosto de 1811 fueron los nueve ejemplares que la junta recibió de Castelli (Cabodi y González, 1972 y Morán, 2019). Lamentablemente, se desconoce qué paradero tuvieron los números enviados por López Aldana. 
Lo importante es que, con este periódico, se inauguró "la confección de una retórica histórica sobre el despotismo en el Perú” (Peralta Ruiz, 2010, p. 211).

No conforme con que su primer papel periódico fuera publicado fuera del Virreinato, López Aldana aprovechó la coyuntura liberal en Lima para emprender la publicación de uno segundo, titulado El Satélite del Peruano o Redacción Política, Liberal e Instructiva, que debía acompañar la aventura liberal de El Peruano, de Gaspar Rico. Si El Peruano representó el primer ensayo de prensa libre orientado a enseńar los valores doctrinales auspiciados por las Cortes de Cádiz, El Satélite se propuso complementarlo con un plan de promoción de la instrucción pública y el fomento de valores liberales entre los ciudadanos. Sin embargo, por interposición del virrey, la "Introducción" de El Satélite, que circuló a fines de febrero, fue denunciada ante la Junta de Censura bajo el cargo de "subvertir el buen orden y la tranquilidad pública". ${ }^{14}$ Concretamente, se acusó a López Aldana de limitar el concepto de patria a "la vasta extensión de ambas Américas", excluyéndose a la metrópoli (Martínez Riaza, 1985, p. 107). López Aldana se propuso rebatir la censura con la publicación un "Suplemento a la Introducción" en el que esclareció que "la España libre de los franceses es nuestra madre patria”. De poco sirvió esta aclaración. El Satélite fue condenado como libelo y los ejemplares de la "Introducción" y el "Suplemento" fueron confiscados en la imprenta donde se editaron. Como consecuencia de esta resolución, López Aldana redactó una extensa defensa dirigida al virrey que tituló "Nulidad del dictamen que pronunció la Junta Censoria” en la que denunció los vicios incurridos por la Junta de Censura y pidió "que se repongan las cosas al estado que tenían antes del 24 de febrero", es decir, que se permitiera circular la "Introducción"

14 Archivo General de Indias, Diversos 2, "Denuncia hecha a esta superioridad del periódico titulado El Satélite del Peruano”. 
y el "Suplemento". Su pedido fracasó. El Satélite del Peruano circuló a fines de marzo y solamente reprodujo artículos de economía y política previamente publicados en periódicos de España y Europa. La aventura periodística contestataria de López Aldana se interrumpió definitivamente en 1812 cuando El Satélite dejó de circular. El abogado bogotano debió aguardar la coyuntura inaugurada por el impacto en el Perú de la independencia chilena para retomar su crítica al despotismo español, pero ahora convertido en corresponsal del general San Martín.

En Lima, López Aldana integró una red de patriotas forasteros, hispanoamericanos con residencia en la capital, que se activó con la llegada del comisionado plenipotenciario Torres. Esta red estaba constituida por unas treinta personalidades, entre las que destacaban el chileno Joaquín Campino, los neogranadinos Mariano López y Miguel Moreno, los bonaerenses Cecilia Tagle y Mariano de Saravia, los salteños Miguel Otero y Felipe Antonio Alvarado, el cordobés Francisco Javier de Echagüe, el tucumano Tomás Forcada, el correntino Pablo Bocanegra, entre otros hispanoamericanos (Leguía y Martínez, 1971, tomo II, p. 274). Es de destacar que dicha red estuvo articulada en torno a hombres que, al apoyar a San Martín, pensaban que, con ello, estaban garantizando la independencia de sus patrias de origen. De todos ellos, fue Campino quien mantendría una estrecha amistad política con López Aldana. Llegado a Lima posiblemente en 1815 en la condición de emigrado, tras la reconquista de Chile por el ejército de Osorio, a su actividad de comerciante añadió unas altas dotes en el terreno de la cultura (Leguía y Martínez, 1971, tomo II, p. 280). La colaboración política entre Campino y López Aldana durante su condición de emisarios sanmartinianos se plasmó en la redacción conjunta de informaciones firmadas con el seudónimo de José Pardo Prieto y Compañía. A este tándem se unió ocasionalmente un extranjero, un residente en la capital de origen europeo, 
el italiano José Boqui. Este personaje se vio implicado en la conspiración de Anchoris de 1812, por lo que tuvo que huir a Buenos Aires. Dos años después, retornó a Lima y se dedicó a actividades de orfebrería, además de inventar máquinas para desaguar minas (Wuffarden, 2009, tomo VIII, p. 787). En esas circunstancias, en 1820, se convirtió en emisario sanmartiniano captado por López Aldana y Campino. Boqui asumió el control del dinero recaudado por López Aldana para la guerra de zapa, cuando este se incorporó al Ejército Libertador.

La conexión entre López Aldana y el coronel Torres es desconocida, y no hay pruebas de que se hubiese dado ni de que aquel adquiriese la condición de emisario por encargo de este. La primera noticia de la colaboración de López Aldana con San Martín se remonta a la época en la que arribó la expedición naval de Cochrane al Callao. Remigio Silva, tras su encuentro con Álvarez Jonte en la O'Higgins y su posterior desembarco clandestino en Lima, fue el encargado de transmitir a López Aldana las instrucciones que antes habían sido proporcionadas a otros emisarios sanmartinianos. Silva también entregó a López Aldana una carta personal de Álvarez Jonte, en la que este le comunicaba que se hallaba encargado por San Martín

de remitir a U. el paquete, que por separado debe entregar el conductor de esta [Silva]. S. E. tiene los más lisonjeros motivos para creer que nadie mejor que U. hará un uso conveniente de los indicados papeles, y se atreve a esperar de que por ellos el conocido talento y patriotismo de U. harán facilitar los grandes resultados que ocupan la atención de la América en este momento. (López Aldana, 1869, p. 29)

Según aclaró Carlos López Aldana en el folleto de vindicación de su padre de 1869, esos papeles consistieron en múltiples ejemplares impresos de la proclama de San Martín dirigida a los habitantes del Perú firmada en Santiago de Chile el 
13 de noviembre de 1818. La parte final de este documento invitaba a los peruanos a abandonar su pasividad y sumarse a la causa independentista, porque "la expectación de más de las otras tres partes de la tierra, están sobre vuestros pasos actuales. ¿Confirmaréis las sospechas que se han excitado contra vosotros en el espacio de nueve años? Si el mundo ve que sabéis aprovechar este feliz momento, vuestra resolución le será tan imponente como la misma fuerza unida de este continente" (CDIP, tomo VIII, vol. 2, p. 509). En consecuencia, Álvarez Jonte encomendó a López Aldana proseguir con la guerra de zapa con el objetivo de socavar la opinión pública fidelista y encaminarla a impedir que "los tiranos cuenten o con una fría indiferencia, o con una ciega resignación de los limeños”. El hombre de confianza de San Martín transmitió a López Aldana que solo "un hombre de la elevación de alma, de la habilidad, del crédito y demás poderosas relaciones que usted posee" podría imponer en la capital el sentido común de la inevitabilidad del cambio de sistema político. Al respecto, Álvarez Jonte confiaba plenamente en que "las opiniones son las que dan existencia a las fuerzas. Se toma la fuerza por la causa, cuando no es sino el efecto, y se cree que es posible servirse del efecto contra la causa. Que las opiniones del pueblo de Lima se decidan en favor de la libertad [...]" (López Aldana, 1869, p. 30).

López Aldana y su círculo de forasteros aceptaron el reto de intentar cambiar la opinión política de la población y difundieron en la capital la proclama de San Martín. Sin embargo, la respuesta a su difusión no fue la esperada y la indiferencia general, en apariencia, persistió. En este estado del relato, resulta necesario hacer una rectificación histórica. Con ocasión del centenario de la independencia argentina, se divulgó, extraída del archivo del historiador Bartolomé Mitre, una misiva a San Martín firmada por primera vez como "el peruano que se llama desde hoy, José Pardo Prieto" el 2 de noviembre de 1819. Sin dudarlo, Mitre la atribuyó a Campino y López 
Aldana, ${ }^{15}$ pero, al leer atentamente este documento, resulta indudable que su autor fue Remigio Silva. Basta con señalar que, en un pasaje de la misiva, se afirma que "fui el primero que visité la escuadra cuando estuvo aquí la vez primera, resultando de esta visita el que por mi plan y arbitrio se socorriese ésta de víveres y aguada" (CDIP, 1971, tomo VIII, vol. 2 , p. 397). Todo lo expuesto en el texto es un resumen de las actividades clandestinas que Silva había realizado o planeaba realizar. Como ejemplo de lo último, el patriota limeño ofreció entregar en el plazo de cuarenta días una respuesta detallada al informe recibido de manos de Álvarez Jonte. De lo anterior, se desprende que, por parte de Mitre, hubo una lamentable confusión al arrebatar la autoría de dicho documento a Silva. En realidad, la primera comunicación enviada por López Aldana y Campino a San Martín fue mucho más tardía, concretamente, cuando la Expedición Libertadora ya había desembarcado en la bahía de Paracas.

El 17 de setiembre de 1820, José Pardo y Prieto remitió al cuartel general de San Martín en Pisco la "Exposición hecho al Excelentísimo Señor don Joaquín de la Pezuela, virrey del Perú, en 17 de agosto de 1820, por un jefe de escuadrón del ejército de Lima”. Este oficial realista no era otro que el brigadier Andrés García Camba, quien escribiría años después la historia del Ejército realista en sus últimos años en el Perú. López Aldana obtuvo el documento que, en sus palabras, "da bastante idea del ejército de esta capital", en las altas esferas del Gobierno virreinal y no dudó en enviárselo a San Martín, en su deseo de responder a al menos a una parte de las instrucciones. En la postdata, el santafereño y el chileno

15 Fue editada en Buenos Aires como "López Aldana a San Martín” por la Comisión Nacional del Centenario (1910, tomo VII, pp. 157-160); esta misiva fue también reproducida en Lima como "Comunicación enviada por el patriota López Aldana a San Martín”, CDIP (1971, tomo VIII, vol. 2, pp. 397-399). 
agregaron que tenían noticias sobre oficiales patriotas en el ejército realista que "los vemos en una indecisión, tristeza y turbación” (Comisión Nacional del Centenario, 1910, tomo VII, p. 182). López Aldana y Campino también comunicaron que existía entre los militares y la sociedad una creciente desafección hacia Pezuela, pero añadieron que "no por esto se debe esperar ninguna cooperación activa de parte de este pueblo patriota, pero inerte, impotente, flojo, tímido" (Comisión Nacional del Centenario, tomo VII, pp. 184-185). Por último, ambos patriotas forasteros recomendaron a San Martín no tener ninguna consideración con los hacendados peruanos, ya que todos eran enemigos de la independencia. Por ello, "bajo de ciertas racionales convicciones", le recomendaron decretar a su llegada la libertad de los negros o esclavos "convidándolos a la bandera de la patria, así como lo ha hecho Bolívar en Venezuela” (Comisión Nacional del Centenario, 1910, tomo VII, pp. 184-185). En suma, el documento manifestaba un menosprecio generalizado hacia los peruanos al considerarlos incapaces de luchar por su propia libertad. Tal fue la postura que mantuvieron los forasteros según se desprende de estas y otras carta de José Pardo Prieto y Compañía.

A diferencia del dinero gestionado por Domingo Torres para garantizar la guerra de zapa en 1818, los forasteros de López Aldana y otros grupos de patriotas tomaron la iniciativa de hacer una colecta clandestina entre la población limeña para obtener los recursos económicos que les permitieran cumplir con el encargo de fomentar un clima de desconcierto entre los realistas. Los aportes en onzas de oro, pesos y reales fueron registrados en un detallado listado publicado por Paz Soldán (1868, pp. 430-431). La administración de este dinero recayó inicialmente en López Aldana. El dinero fue especialmente usado por este para prolongar la guerra de zapa que, al igual que en la época de Domingo Torres, consistió en pagar por la obtención de información confidencial del Gobierno, 
hacer labores de propaganda y promover la división dentro del ejército realista. Precisamente -afirma López Aldana-, esta última fue vital para que el batallón Numancia, integrado en su mayor parte por soldados de origen venezolano y neogranadino, desertara en Chancay bajo la conducción del general Tomás Heres y se incorporara al ejército libertador en Supe.

En una carta remitida el 3 de noviembre de 1820 a San Martín por José Pardo Prieto y Compañía, en la que se le comunicaban los detalles de cómo se estaba produciendo la deserción del batallón Numancia, casi al final, se insistió en opinar sobre el estado del patriotismo limeño. López Aldana y Campino afirmaron:

cada día con este motivo, admiramos más y por eso lo repetimos que en las diversas asociaciones o reuniones que hay en esta ciudad de patriotas para coadyuvar en lo que puede cada miserable, que lo somos en efecto, al éxito de la causa, y de todos los que estamos bastante iniciados, apenas se encuentra un Limeńo que haya hecho el menor esfuerzo con su persona o con un real para nada, y los dichos se componen de Santafereños, Caraqueños, Quiteños, Porteños, Chilenos, Extranjeros, Serranos en fin, todos de fuera de Lima; y no es porque los Limeños dejen casi todos de desear la independencia para figurar, sino porque no quieren comprometerse y así dicen muchos de ellos, que no hay necesidad de que ninguno haga nada pues ya está San Martín aqui y él lo ha de hacer todo. ${ }^{16}$ (Paz Soldán, 1868, p. 108)

La historiografía peruana de la segunda mitad del siglo XIX cargó en contra de esta afirmación. Uno de los principales defensores de la implicación de los limeños en labores de espionaje patriótico fue Francisco Javier Mariátegui. Este, en su crítica a la historia de la independencia de Paz Soldán, aseveró que no solo los forasteros estuvieron involucrados "en

16 Las cursivas son nuestras. 
reducir a la oficialidad americana, para disponerla a hacer lo que Numancia”, sino también los rivagüerianos y los carolinos. Agregó Mariátegui que los forasteros se desactivaron pronto porque su líder, López Aldana, se enroló en el ejército libertador en enero de 1821. Seguidamente, enfiló contra el santafereño y su grupo por hacer "alarde de despreciar a los peruanos y especialmente a los limeńos” (Mariátegui, 1869, p. 18). No contento con ello, Mariátegui calificó a López Aldana de pusilánime por abandonar tempranamente la guerra de zapa y de expresarse con abierta ligereza de los hechos. En otras palabras, la descalificación política de los limeños que contuvieron las misivas de José Pardo Prieto y Compañía provocó que López Aldana y su grupo de forasteros fueran estigmatizados como exagerados protagonistas de la independencia en detrimento del patriotismo limeño. José de la Riva Agüero, en sus estudios sobre la emancipación, les ignoró, y Leguía y Martínez, en su Historia del protectorado, se expresó sarcásticamente en contra de ellos. Los emisarios sanmartinianos forasteros fueron olvidados por la historiografía peruana por generar incomodidad y alimentar el discurso de la independencia concedida.

López Aldana participó como plenipotenciario del general San Martín en las negociaciones de paz celebradas con la representación realista del virrey José de la Serna en la hacienda Punchauca a principios de mayo de 1821 (De la Puente Candamo, 2000). Concretamente, ejerció como secretario en su condición de "vocal nombrado de la Cámara de Apelaciones de Trujillo" (Martínez Riaza y Moreno Cebrián, 2014, p. 128). En agosto de 1821, fue elevado al cargo de vocal de la Alta Cámara de Justicia creada por el Protectorado y, en diciembre, San Martín le confirió la Orden del Sol en el grado de benemérito. En su condición de magistrado, López Aldana llegó a desempeñarse como decano y auditor de guerra. Su trayectoria en la justicia se interrumpió el 5 de febrero de 1824, cuando fue hecho prisionero por los realis- 
tas con ocasión de la rebelión en la fortaleza del Callao del ejército de los Andes, liderada por el general mendocino Dámaso Moyano. Tras su arresto, fue recluido en la prisión de la isla Esteves o Chucuito, en Puno. Su liberación se produjo inmediatamente después de la batalla de Ayacucho. Bolívar le nombró vocal de la Corte Suprema de Justicia, cargo en el que se desempeńó entre 1825 y 1831 , cuando fue destituido por el jefe encargado del mando supremo de la república Andrés Reyes y Buitrón. López Aldana inició una demanda ante el Congreso peruano para que se le reconociera en calidad de pensión "los dos tercios del sueldo de su último empleo a los que hayan servido de 20 a 30 años" (López Aldana, 1832, p. 10). Para probar esa condición, el exmagistrado remontó sus servicios a los años en que escribió el Diario Secreto de Lima y publicó El Satélite del Peruano en contra del régimen virreinal; añadió como servicios al Perú "la comisión que ejercitó el ańo de 1820, como agente secreto del general San Martín, en esta capital" (López Aldana, 1832, p. 28). El Congreso dio por válidos esos méritos y aprobó su solicitud.

\section{Conclusión}

A partir de dos casos, Remigio Silva y Fernando López Aldana, en este trabajo, se ha demostrado la necesidad de abordar el problema desde una perspectiva transfronteriza, es decir, con una óptica metodológica que supere el encasillamiento nacionalista y privilegie el análisis de las conexiones más allá de las fronteras del virreinato del Perú. En ese sentido, comprender la actuación de Silva como corresponsal o agente de San Martín ha implicado estudiar su vínculo con dos redes chileno-rioplatenses de espionaje entre 1817 y 1820, la primera liderada por el general Domingo Torres y la segunda por Antonio Álvarez Jonte. En el caso de López Aldana, su inicial actuación como emisario fue liderar, en Lima, el grupo de forasteros de origen chileno, rioplatense, quiteño, neogranadino y novohispano. Se ha demostrado que su con- 
dición de emisario sanmartiniano ocurrió cuando se vinculó tardíamente a la red de Álvarez Jonte, circunstancia que lo obligó a abandonar a los forasteros.

Otro aspecto abordado en este trabajo fue la contradictoria actuación de los emisarios sanmartinianos, que condujo en ocasiones a disputas, malentendidos y enemistades entre ellos. La competencia entre Silva y los emisarios Francisco Fernández Paredes y José García por ser los primeros en informar a la escuadra de Lord Cochrane es el más paradigmático de estos casos de discordias personales. En el caso de López Aldana, destacó su actitud, junto con el chileno Joaquín Campino, de descalificar a los grupos patriotas limeños sin tener un conocimiento certero acerca de estos últimos. Ello condujo a su marginación como protagonistas por parte de la historiografía peruana de la independencia de fines del siglo XIX y principios del XX.

Por todo lo anterior, se puede concluir que la historia de los emisarios sanmartinianos en el Perú todavía requiere de un estudio desapasionado. No se trata de suscribir el discurso de la independencia concedida. De lo que debería preocuparse un historiador en vísperas de la conmemoración del bicentenario de 1821 es en pensar la independencia del Perú como el espacio de confluencia final y definitiva de múltiples idearios, proyectos y sentimientos políticos que trascendieron su realidad territorial.

212 Recibido: 03 de agosto de 2020

Aprobado: 25 de noviembre de 2020 


\section{Referencias bibliográficas}

Alvarado, P.

"La reconquista imposible: planes político-militares del virrey Pezuela frente a la independencia de Chile, 1817-1818”. Artificios. Revista Colombiana de Estudiantes de Historia, (3), 108-131.

Burzio, H. F.

"Dr. Fernando López Aldana, agente secreto de San Martín en el Perú". Boletín de la Academia Nacional de la Historia, 36, 290-426.

Cabodi, J. J. y González, J. C.

"La reimpresión bonaerense del Diario Secreto de Lima (1811)". Quinto Congreso Internacional de Historia de América, Lima, Comisión Nacional del Sesquicentenario de la Independencia del Perú, tomo III, pp. 182-195.

Colección Documental de la Independencia del Perú (CDIP).

(1971) La Expedición Libertadora. Gustavo Pons Muzzo (Recop.), tomo VIII.

Comisión Nacional del Centenario.

(1910) Documentos del Archivo de San Martín, tomo VII. Imprenta de Coni Hermanos.

Eguiguren, L. A.

(1957) Guerra separatista. La tentativa de rebelión que concibió el doctor José Mateo Silva en Lima. Imprenta López.

Leguía y Martínez, G.

(1972) Historia de la emancipación del Perú: el Protectorado. Comisión Nacional del Sesquicentenario de la Independencia del Perú. 
López Aldana, C.

(1869) El doctor D. Fernando López Aldana ante la historia. Réplica al Doctor Don Francisco Javier Mariátegui y a un anonimista. Imprenta de El Comercio por J. R. Sánchez.

López Aldana, F.

(1832) Expediente que sigue el C. Fernando López Aldana, antiguo magistrado del Perú libre, sobre su sueldo, con motivo de la destitución que sufrió en 24 de agosto de 1831. Imprenta de José María Masías.

Martínez Riaza, A.

(1985) La prensa doctrinal en la independencia de Perú 18111824. Instituto de Cooperación Iberoamericana.

Martínez Riaza, A. y Moreno Cebrián, A.

(2014) "La conciliación imposible. Las negociaciones entre españoles y americanos en la independencia del Perú, 1820-1824". En A. Martínez Riaza (Ed.), La independencia inconcebible. España y la "pérdida" del Perú (1820-1824) (pp. 99-211). Instituto Riva Agüero y Pontificia Universidad Católica del Perú.

Mitre, B.

(1889) Historia de San Martín y de la Emancipación SudAmericana. Félix Lajouane editor.

Morán, D.

(2019) "De manuscrito conspirador a impreso revolucionario. 'El Diario Secreto de Lima' y el discurso político disidente en el contexto de la independencia de América”. Historia y Comunicación Social, 24 (1), 201-216.

Olivero, S. F.

(2009) "Bernaldes Polledo, José". Diccionario Biográfico Español. Real Academia de la Historia. 
Pavón Pereyra, E.

(1954) "La guerra de zapa (El servicio de informaciones en las campañas de Chile y de Perú)". Revista de la Universidad Nacional del Litoral, (28), 273-293.

Paz Soldán, M. F.

(1868) Historia del Perú independiente. Primer período 18191822. Imprenta de Alfonso Lemale.

Peralta Ruiz, V. (2010). La independencia y la cultura politica peruana (1808-1821). Instituto de Estudios Peruanos y Fundación M. J. Bustamante de la Fuente.

Peralta Ruiz, V. (en prensa).

"Tramando la independencia. Los agentes secretos del general San Martín en el Perú (1817-1820)”. En C. McEvoy (Ed.), La Expedición Libertadora: entre el océano Pacífico y los Andes. Instituto de Estudios Peruanos (en prensa).

Puente Candamo, J. de la.

(2000) San Martín y el Perú. Planteamiento doctrinario. Editorial Nueva Mayoría.

Silva, R. B.

(1921) Tres patriotas peruanos. El coronel Dn. Remigio Silva y sus hermanos el abogado Dn. Mateo y Doña Brigida. Su actuación en favor de la independencia de Chile y del Perú. Imprenta de El Callao.

Vicuña Mackenna, B.

(1860) La revolución de la independencia del Perú. Imprenta de El Comercio por J. M. Monterola.

Wuffarden, L. E.

(2009) "Boqui, José”. Diccionario biográfico español. Real Academia de la Historia. 
